\title{
Electron Metallography of Alloy 718
}

\author{
John F. Radavich \\ Emeritus Professor \\ Purdue University \\ West Lafayette, IN 47907
}

\begin{abstract}
Alloy 718 is unique in that it forms the greatest number of phases due to its composition and the large variety of imposed heat treatments. The microstructures produced can vary in size, distribution, and location. Some of the large structures can be resolved optically but for resolution of $\gamma^{\prime \prime} / \gamma^{\prime}$ phases, the SEM and/or TEM is required.

The normal metallographic preparation for Alloy 718 is a mechanical polish plus an immersion etch in a suitable acid solution. However, it has been found that the use of an electrolytic polish plus electrolytic etch yields more consistent results. In addition, the use of the electrolytic preparation reveals more consistently the phases and helps define the thermal behavior of the alloy. The electrolytic preparation will be described and examples of microstructures representing various thermal conditions will be presented.
\end{abstract}

\section{Introduction}

The prime objective of metallography is to understand the relationship of composition, processing, and mechanical behavior to the microstructure. Much of superalloy metallography can be considered as an "art," but with the current analytical tools and our understanding of phase behavior, metallography of alloy 718 has become closer to being a "science."

While alloy 718 is the most widely used super alloy in cast, wrought, and powder applications, it is also one of the most segregation prone alloys. Depending on ingot size, $\mathrm{Nb}$ segregation, and thermal treatments, a whole range of phases can form during extended times in service at elevated temperatures. The most important of these phases are the $\gamma$ " precipitates which are the order of $100-200 \AA$ in size.

The detection of fine $\gamma^{\prime \prime}$ or $\gamma^{\prime}$ precipitation in alloy 718 requires that the flow layer from the mechanical polish be removed and the $\gamma$ " particles be brought in relief in order for them to be resolved in the SEM or TEM. It has been found that conventional mechanical polishing and immersion etching does not reveal equally well the various phases that can be present in alloy 718. In many cases depending on the thermal treatments, the corrosion behavior of the alloy can necessitate stronger acid solutions or longer etching times or both.

Electrolytic preparation for characterization of alloy 718 has been used for over 25 years with greater success than with mechanical preparation (1). The electrolytic technique has been found to be easy to use, fast, produce consistent results, and yield ideal samples for SEM characterizations.

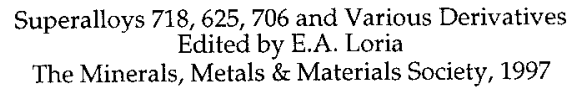




\section{Electrolytic Preparation}

The simple set up for electropolishing consists of a DC power supply, a $250 \mathrm{ml}$ stainless beaker as the cathode, and stainless steel tongs as the anode. After a 6 micron diamond polish, the sample is electropolished for 20 seconds at 25 volts in a solution of $20 \% \mathrm{H}_{2} \mathrm{SO}_{4} .80 \%$ methanol. The sample is rinsed in hot water and fresh alcohol and then cleaned ultrasonically in fresh alcohol.

The electropolished surface is freed of the flow layer and the inert carbides, borides, nitrides and oxides are revealed due to the difference of the electropolishing action. The delta, $\gamma^{\prime \prime}$, and $\gamma$ ' phases are polished flat and need to be etched to reveal these phases.

The electropolished sample is etched at 5 volts for 5-10 seconds in a solution of $170 \mathrm{cc}$ $\mathrm{H}_{3} \mathrm{PO}_{4}, 10 \mathrm{cc} \mathrm{H}_{2} \mathrm{SO}_{4}$, and 15 grams of $\mathrm{CrO}_{3}$ and rinsed as in the electropolishing step. The $\delta$, $\gamma^{\prime}$, and $\gamma^{\prime}$ phases should be in relief while $\alpha \mathrm{Cr}$ and $\sigma$ phases are etched out.

If the sample is in a solution conditioned where the $\delta$ phase is absent, the grain boundaries will not be delineated by the electro-etch. In such cases, to gain contrast at the grain boundaries, the electropolished sample can be immersion etched in a solution of $50 \mathrm{cc} \mathrm{H}_{2} \mathrm{O}, 25$ $\mathrm{cc} \mathrm{HCl}, 5 \mathrm{cc} \mathrm{HF}$ and $2 \mathrm{cc} \mathrm{H}_{2} \mathrm{O}_{2}$.

Because the electropolish and etch reveals all the structures produced by different thermal treatments, high contrast can be obtained in the SEM due to the high yield of secondary electron from the precipitation morphologies. In addition, those phases which have low atomic number elements will produce fewer secondaries compared to precipitates composed of high atomic number elements; thus, different phases or areas will show up due to differences of secondaries.

Because of the very small size of the $\gamma^{\prime \prime} / \gamma^{\prime}$ phases, the highest resolution of the SEM should be used. Magnifications of $10,000 \mathrm{X}$ to $30,000 \mathrm{X}$ should be used since the size of the electron beam determines the resolution of the SEM.

\section{Examples of Electrolytic Preparation}

Examples of structures produced by electrolytic preparation have been selected from various studies ranging from cast, wrought, and long time exposed materials. The structures within these figures will illustrate some of the results that come from the electrolytic preparation.

The first three figures show the wide range of segregation structures found in castings. The bright areas represent areas high in atomic number which must be $\mathrm{Nb}$ rich areas while the dark areas are regions void of precipitation. The small black islands within the white areas are MC and Laves phases which have been polished flat and so do not contribute secondary electrons from a topography factor. As the magnification is increased, the wide range of $\delta$ phases present are revealed.

Figures $1 \mathrm{a}, \mathrm{b}$ and $\mathrm{c}$ are segregation patterns in as-cast alloy 718 , while Figure $1 \mathrm{~d}$ shows at higher magnification the structure in the bright areas in Figure 1c. The darker islands within the picture are Laves phase.

Figure 2 represents the segregation pattern in a Micro-Cast 718 sample which has been heat treated at $1600^{\circ} \mathrm{F}$ for 1 hour. Figure $2 \mathrm{~b}$ shows the darker areas wherein only a few $\gamma^{\prime \prime} / \gamma^{\prime}$ particles are present as contrasted to a dense precipitation of $\gamma^{\prime} / \gamma^{\prime}$ in the white areas of Figure $2 \mathrm{c}$. From the lack of secondary emission, the dark areas are lower in $\mathrm{Nb}$ content than the bright areas.

Figure 3 represents structures in a spray cast plus HIPed 718 sample. Figure $3 a$ shows less contrast of black and white areas which signifies more uniform $\mathrm{Nb}$ content and $\gamma^{\prime \prime} / \gamma^{\prime}$ precipitation. Figure $3 \mathrm{~b}$ shows the grain structure after an immersion etch while Figure $3 \mathrm{c}$ 


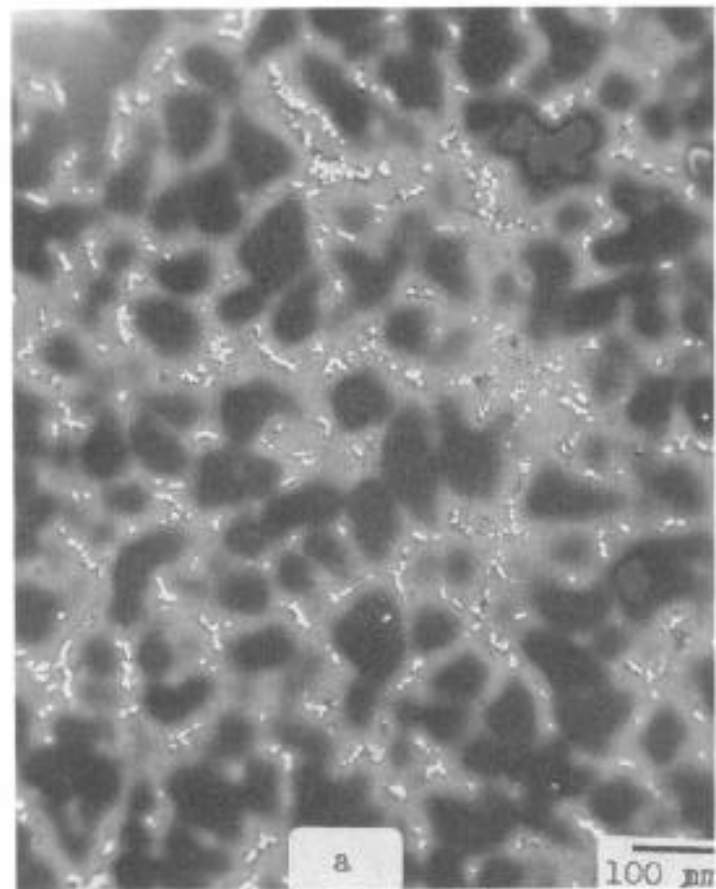

$100 x$

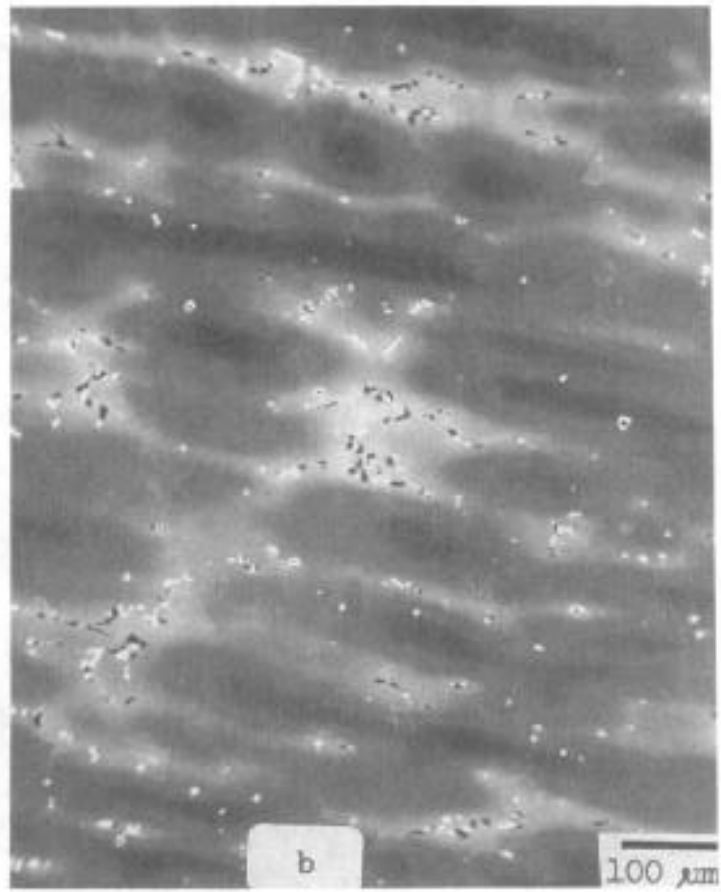

$100 x$

Figure 1 Segregation Patterns in Cast 718

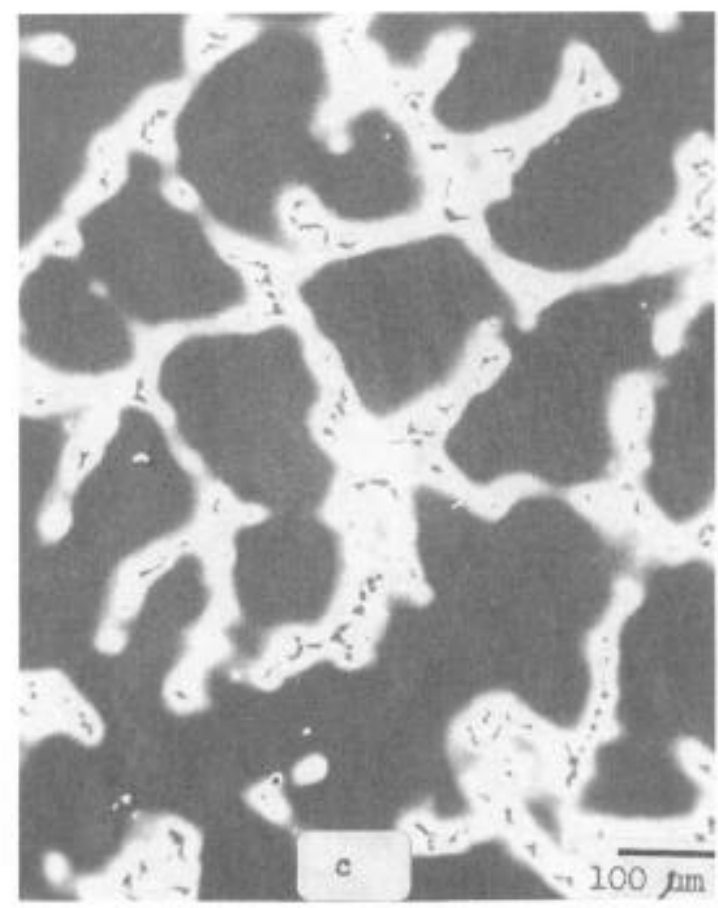

$100 x$

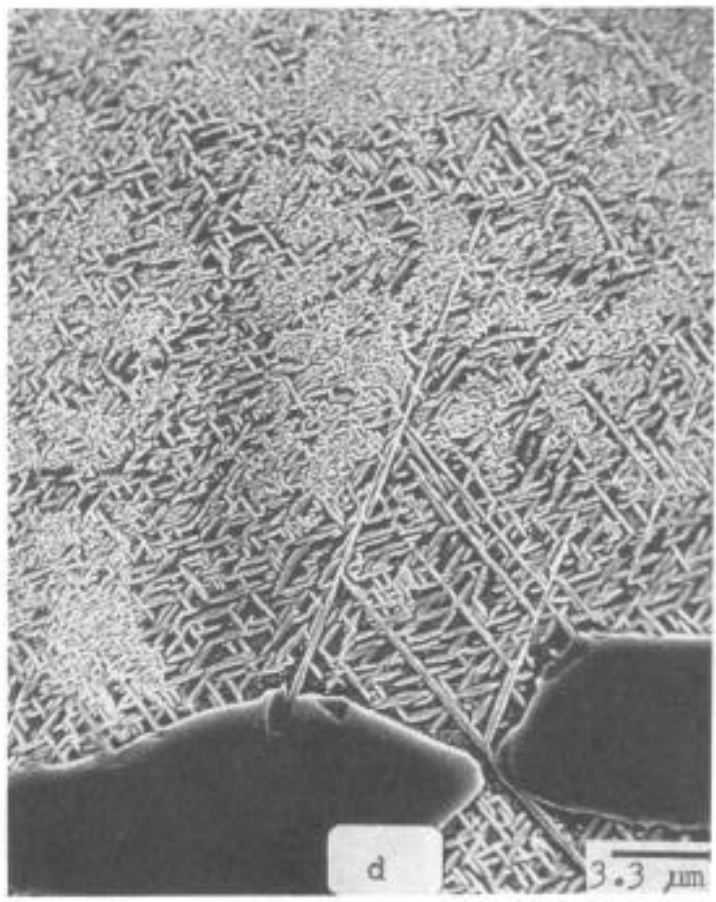

$3 \mathrm{~K}$ 


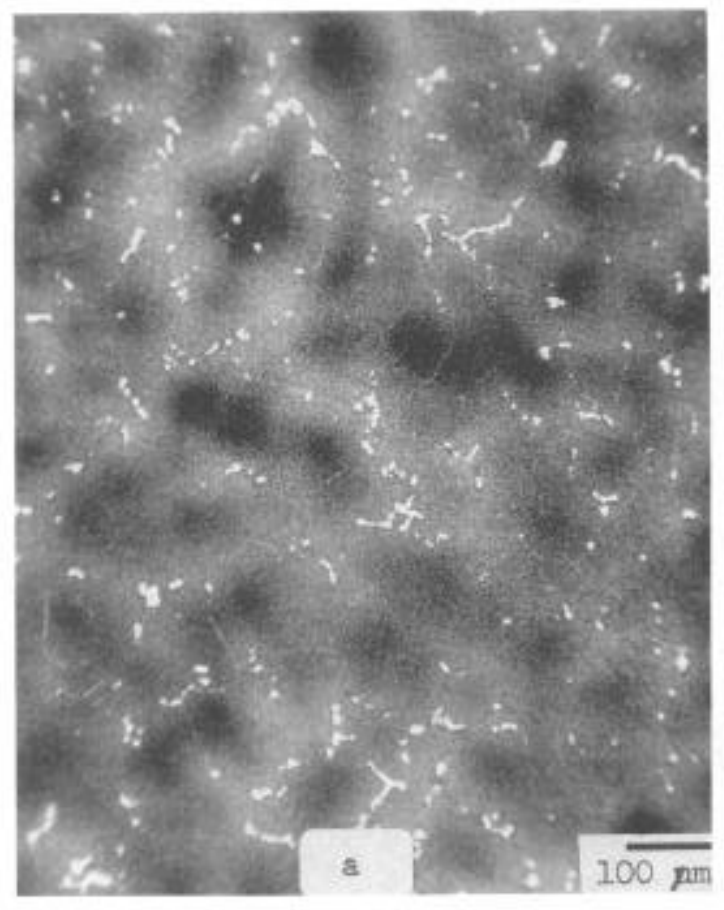

$100 x$

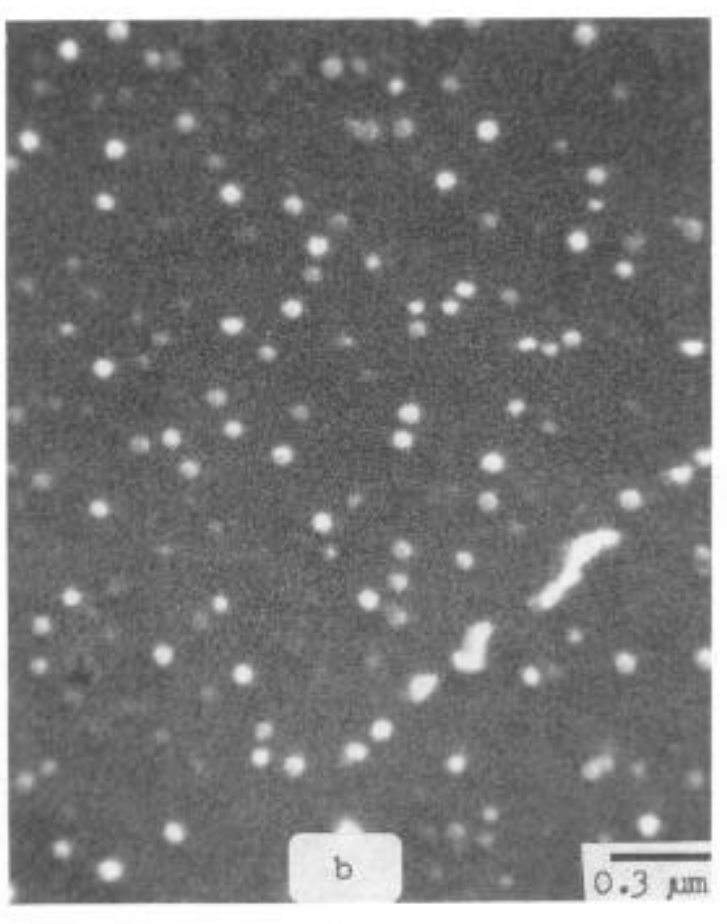

$30 \mathrm{~K}$

Figure 2 Segregation in Micro-Cast $718+1600^{\circ} \mathrm{F} / 1 \mathrm{~h}$

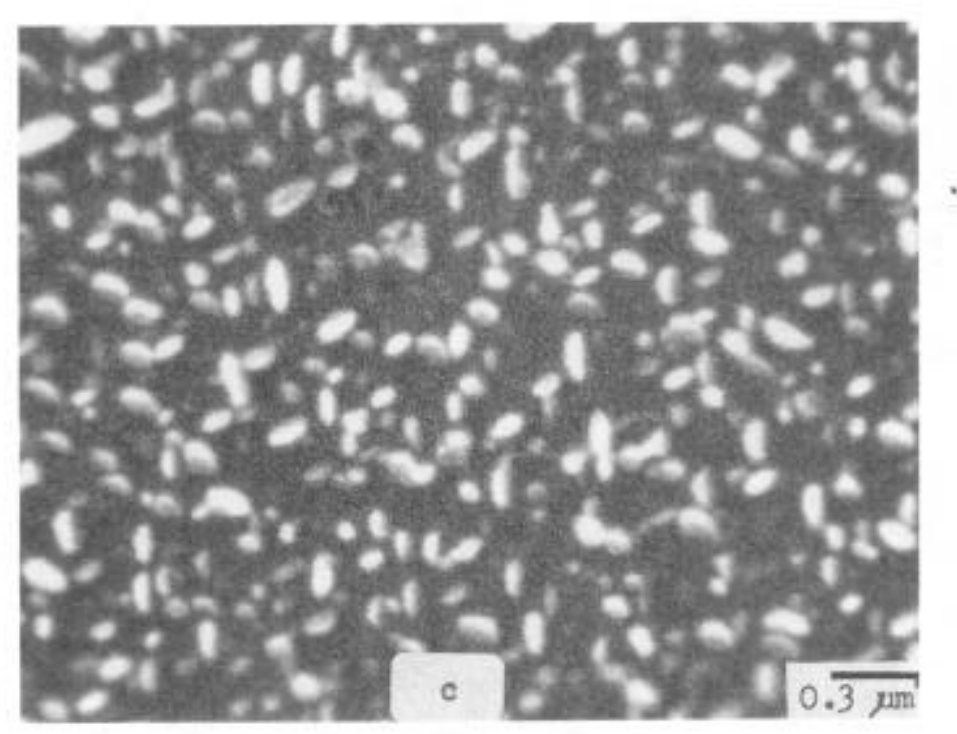

$30 \mathrm{~K}$ 


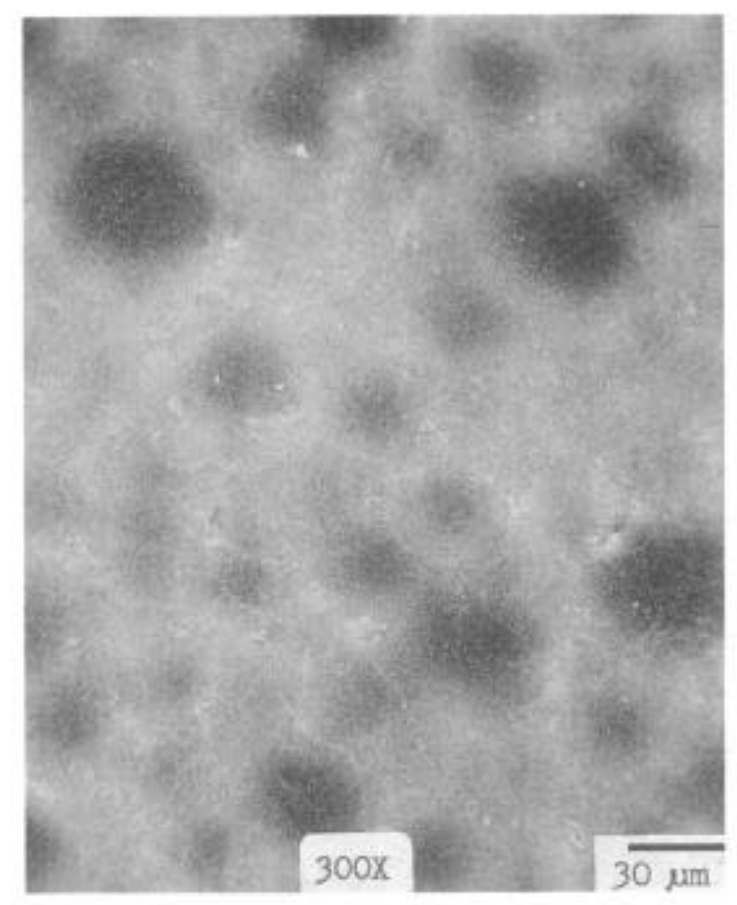

a-As Cast

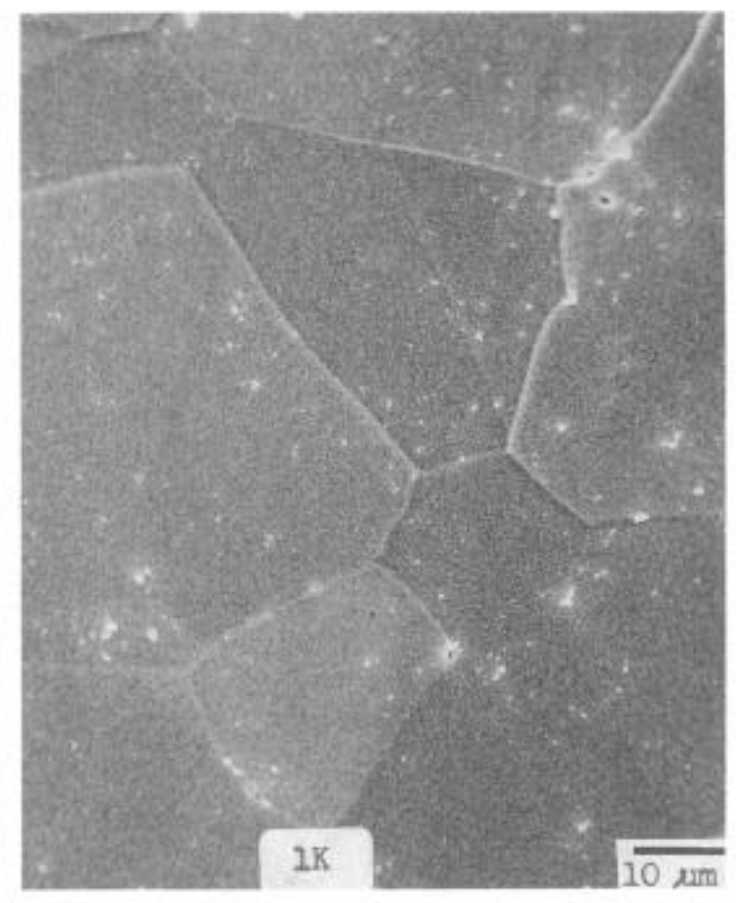

b- Etched

Figure 3 Spray Cast $718+$ HIP

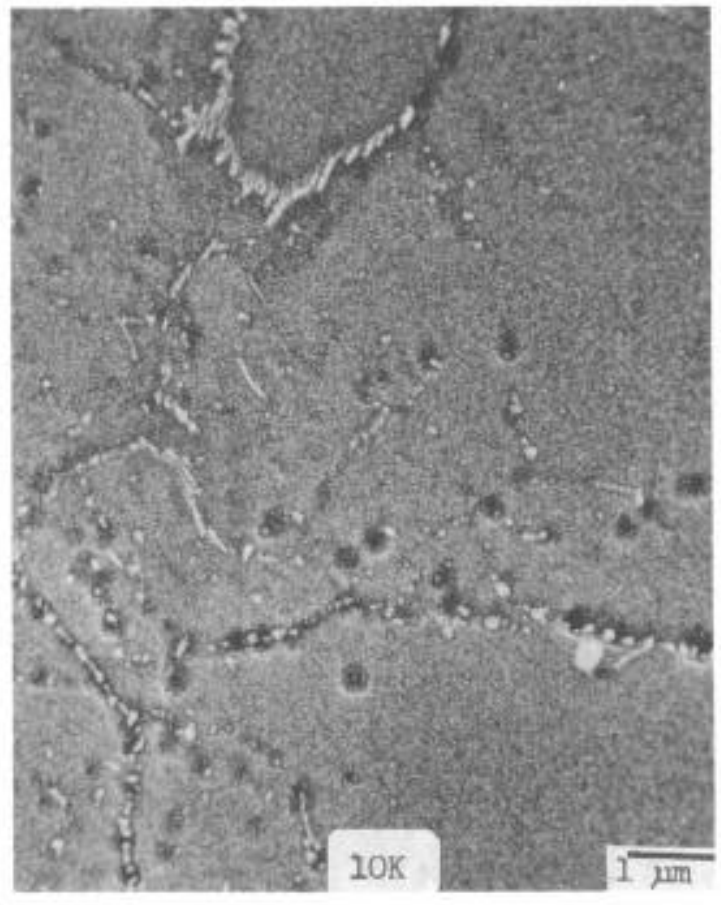

$c-\gamma "$ Phase

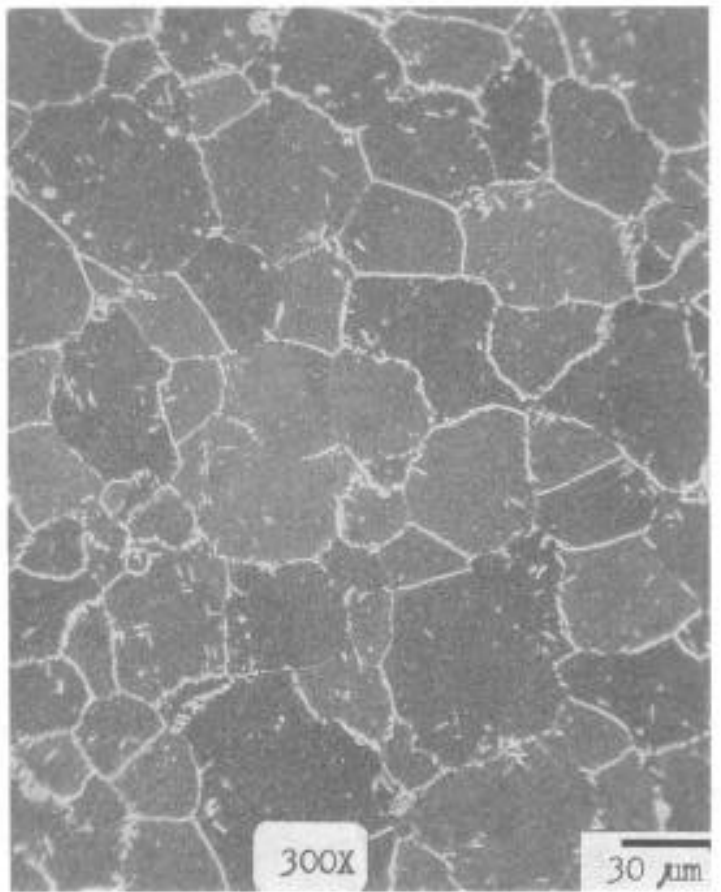

$\mathrm{d}-1200^{\circ} \mathrm{F} / \mathrm{KK}$ 


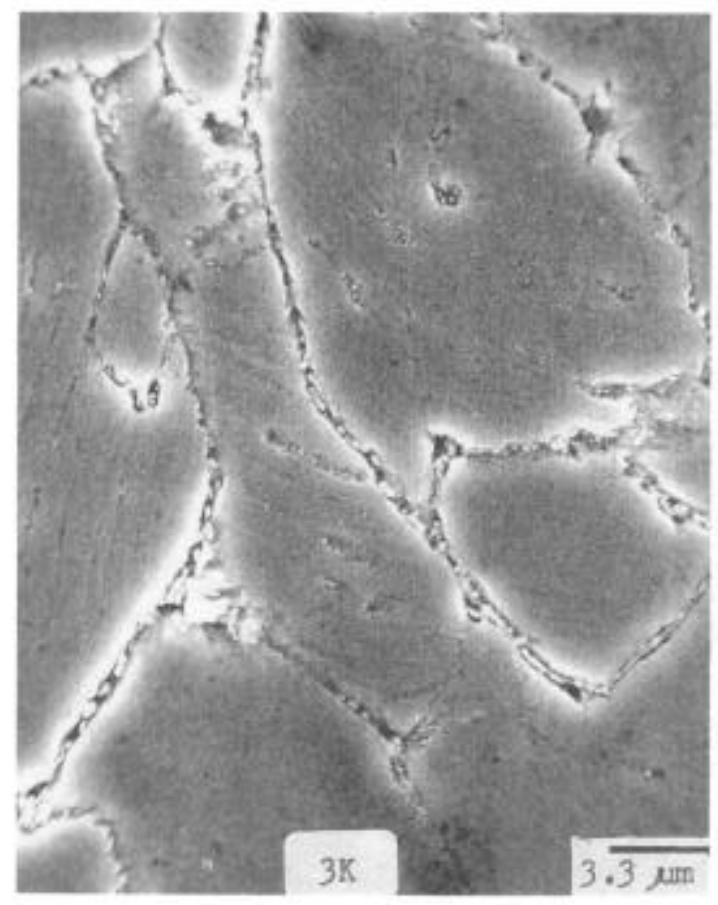

a-Mech Pol

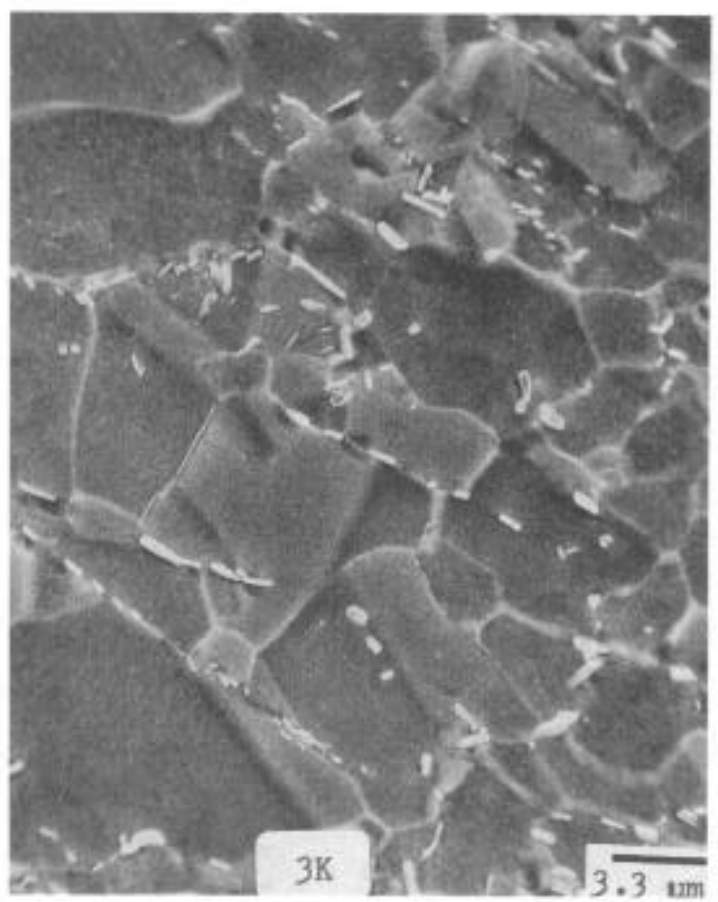

b- Elec Pol

Figure 4 Effects of Mechanical vs Electrolytic Preparation

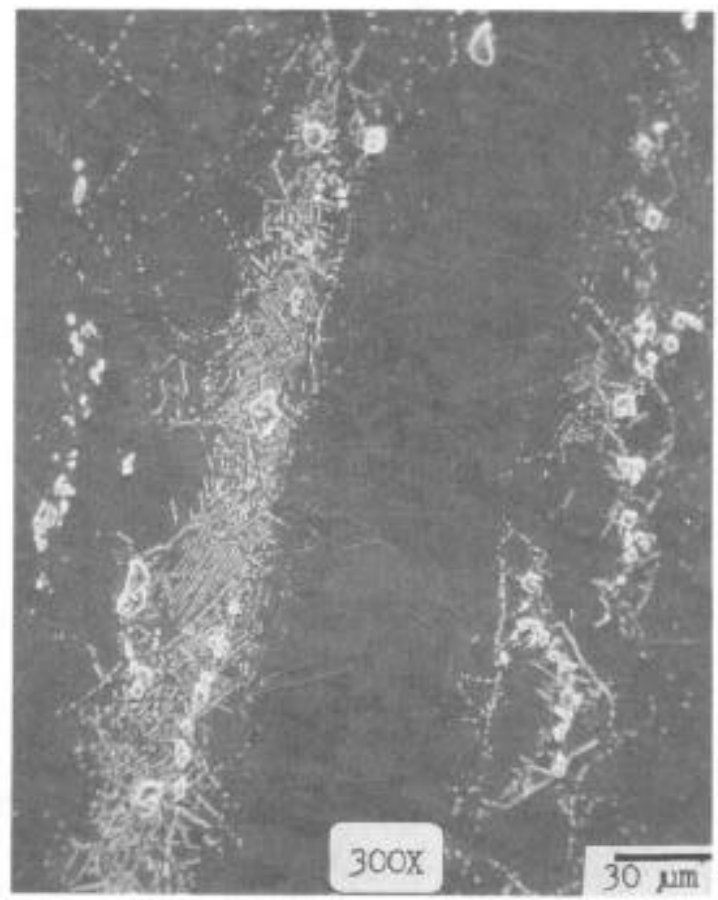

a $-1875^{\circ} \mathrm{F} / \mathrm{lh}$

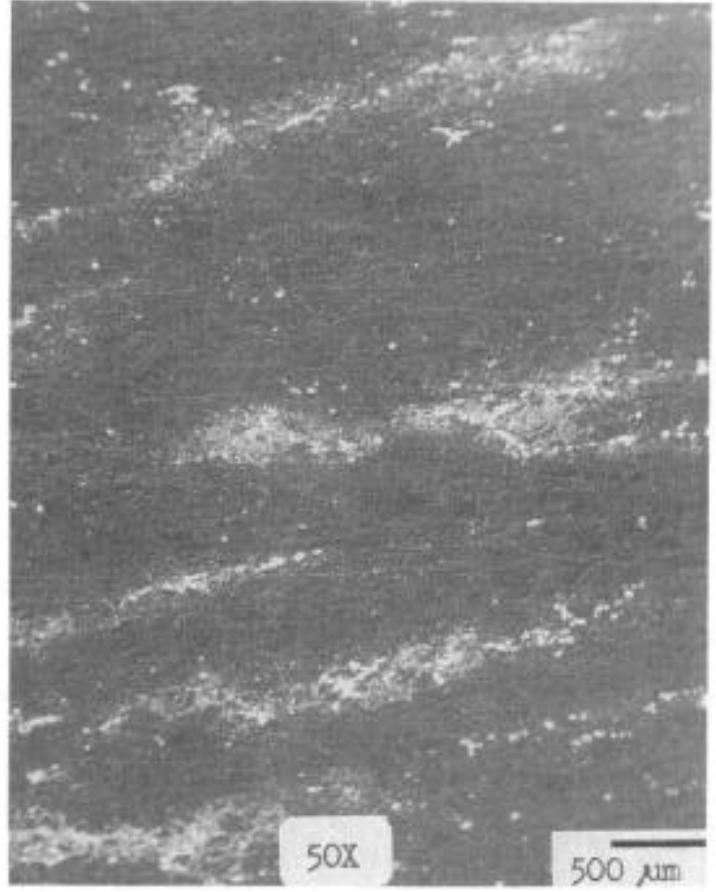

b-Rehomogen

Figure 5 Segregation of Delta Phase 


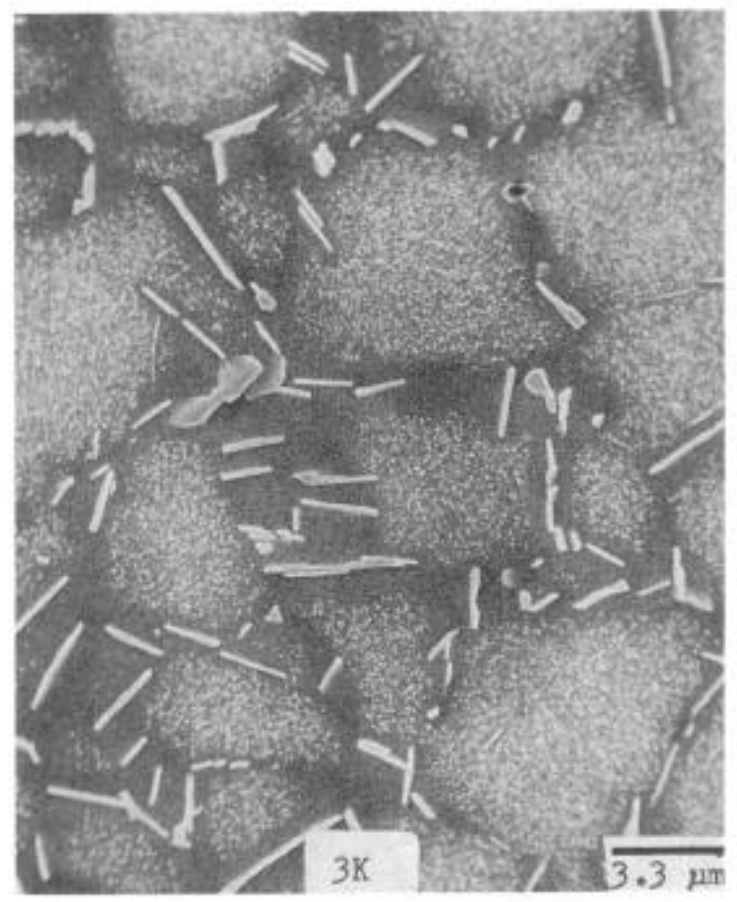

$\mathrm{a}-1600^{\circ} \mathrm{F} / \mathrm{lh}$

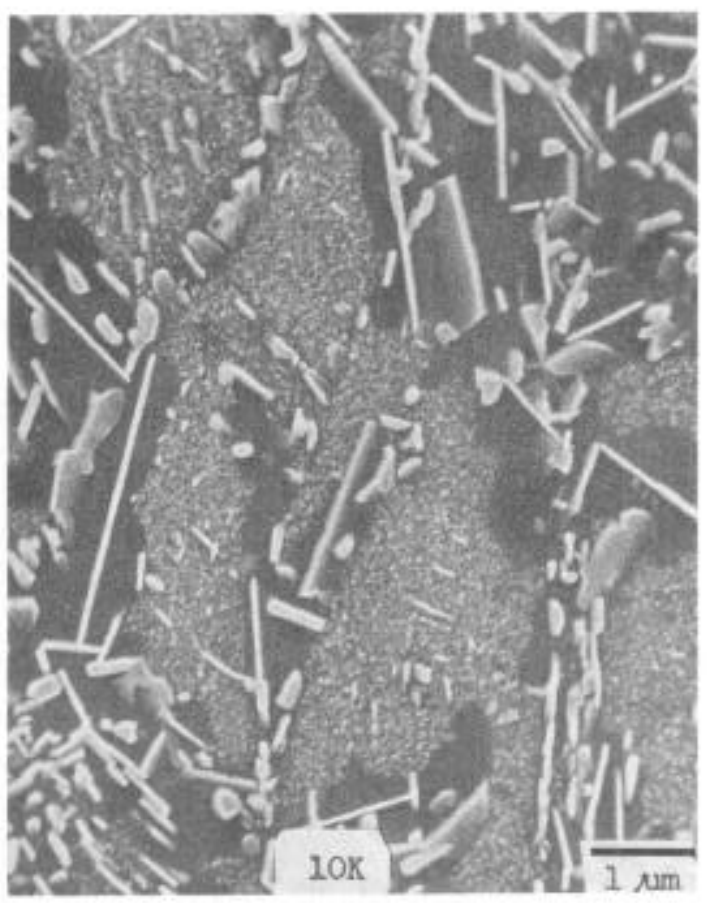

$\mathrm{b}-1400^{\circ} \mathrm{F} / 10 \mathrm{~F}$

Figure $6 \gamma^{\prime \prime}$ Depletion Due to Delta Phase
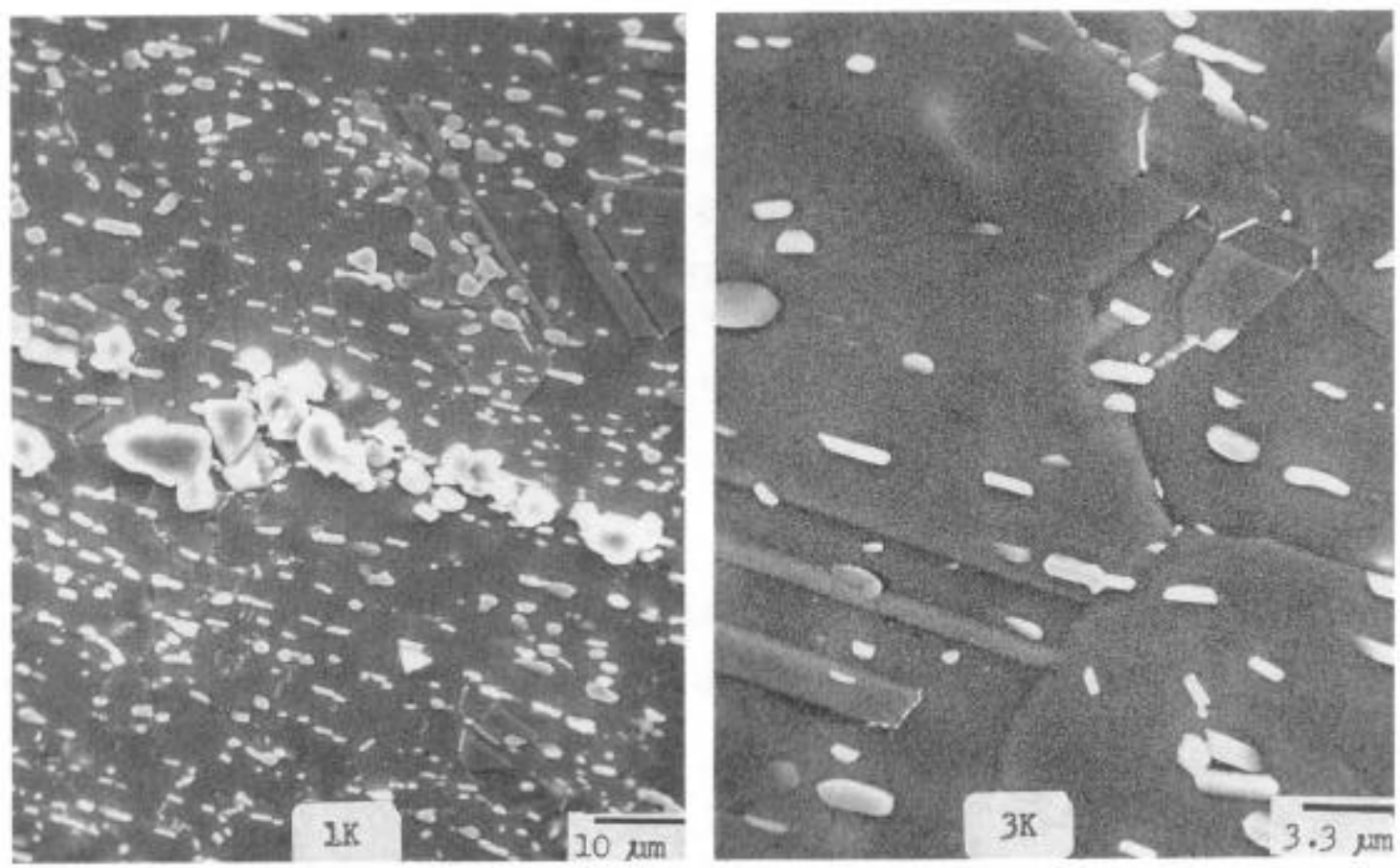

Figure $7 \quad M C+T i N$ Stringers in Billet 718 

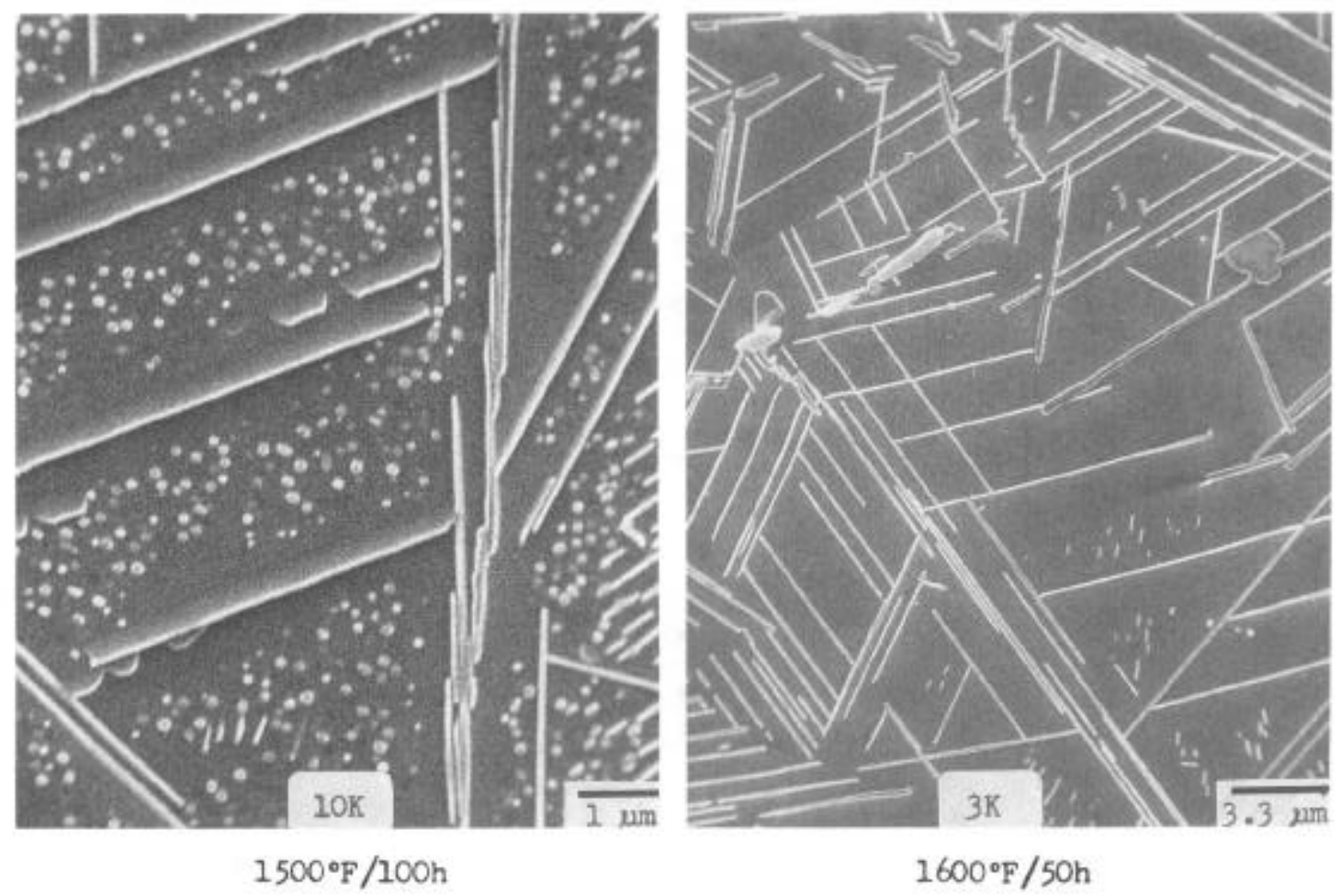

Figure 8 Oreraged 3 tructures in 718

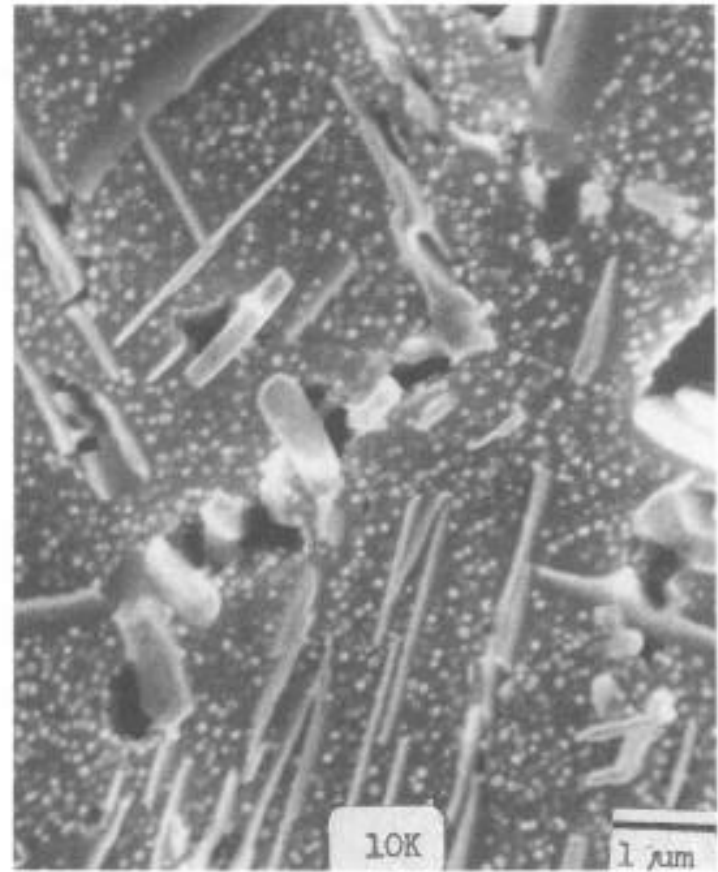

Reg. Prep.

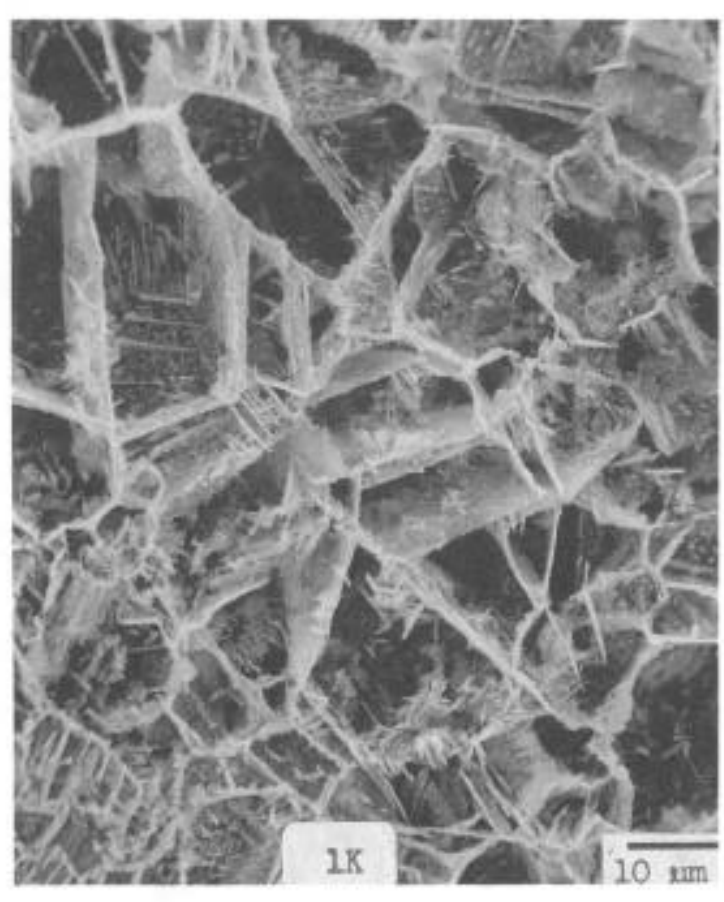

Elec. Prep.

Figure 9 Effects of Long Time Exposures at $1200^{\circ} \mathrm{F}$ 
shows the presence of cooling $\gamma^{\prime \prime} / \gamma^{\prime}$ particles when electro-etched with $\mathrm{CrO}_{3}$. The immersion etch does not show these fine precipitates. Figure $3 \mathrm{~d}$ shows the $\delta$ phase at the grain boundaries of a spray cast plus HIPed sample after a $1200^{\circ} \mathrm{F} / 100$ hour exposure. Figure 4 illustrates the different structural appearance of the same sample after a mechanical polish and etch vs. an electropolish and etch. The grain boundaries are quickly etched in the mechanical preparation before the complete removal of the flow layer and any $\gamma^{\prime \prime} / \gamma^{\prime}$ precipitates would not be detected.

The electrolytic preparation is useful in characterizing segregation in wrought samples of alloy 718. Figure 5a shows delta segregation in the form of stringers after 1 hour at $1875^{\circ} \mathrm{F}$. Figure 5b shows the decrease of stringering after the sample was re-homogenized and forged. The appearance of delta phase after a $1875^{\circ} \mathrm{F}$ solution treatment signifies $\mathrm{Nb}$ segregation and varying delta solvus temperatures which can lead to mixed grain size material. $\mathrm{Re}-$ homogenization is necessary to insure uniform phase precipitation.

Figure 6 illustrates more subtle $\mathrm{Nb}$ segregation by the presence or absence of $\gamma^{\prime \prime} / \gamma^{\prime}$ after a 1-hour heat treatment at $1600^{\circ} \mathrm{F}$ or longer time at $1400^{\circ} \mathrm{F}$. Figure 6 a shows $\gamma^{\prime \prime}$ depletion in the regions of $\delta$ phase precipitation when given 1 hour at $1600^{\circ} \mathrm{F}$ while Figure $6 \mathrm{~b}$ shows a similar $\gamma^{\prime \prime}$ depletion near $\delta$ plates after 10 hours at $1400^{\circ} \mathrm{F}$. The $\mathrm{Nb}$ content necessary for $\gamma^{\prime \prime}$ formation is $4 \%$ or higher and areas with less than this amount will not form $\gamma$ ".

Billet material containing appreciable stringers are unacceptable for quality forgings. Figure 7 shows unacceptable billet structure due to stringers containing MC, TiN, and/or Laves phase. No $\gamma^{\prime \prime} / \gamma^{\prime}$ phases are present in this material as it has not been aged.

Figure $8 \mathrm{a}$ represents the types of overaged structures in alloy 718 after 100 hours at $1500^{\circ} \mathrm{F}$ while Figure $8 \mathrm{~b}$ shows only delta phase after 50 hours at $1600^{\circ} \mathrm{F}$. The $\gamma^{\prime \prime} / \gamma^{\prime}$ transition to $\delta$ phase has taken place as the temperature is raised to $1600^{\circ} \mathrm{F}$.

Alloy 718 is normally used up to $1200^{\circ} \mathrm{F}$ because the transition of $\gamma^{\prime \prime} / \gamma^{\prime}$ to $\delta$ phase occurs with increased exposure times. In exposures of 25 to $50 \mathrm{~K}$ hours, delta, $\alpha \mathrm{Cr}$, and $\gamma^{\prime}$ phases are found and can be related to lower yield stress and hardness $(2,3)$. However, impact tests show only $20 \%$ of the original charpy energy is present in these long exposures at $1200^{\circ} \mathrm{F}$ without a structural relationship. Because impact behavior is related to grain boundary structures, grain boundary structural studies are currently being carried out using modified electrolytic techniques on longtime exposed 718 samples.

Figure 9a shows typical microstructure of longtime exposed samples at $1200^{\circ} \mathrm{F}$. Grain boundary structures brought out by a modified electrolytic technique are shown in Figure $9 \mathrm{~b}$ and 9c. The grain boundaries show film-like structures which form a honeycomb network and affect the impact behavior.

\section{Conclusions}

The use of the electrolytic preparation techniques have become standard preparation methods to better understand the structural responses in alloy 718 . The electrolytic technique works equally well on cast, wrought and powder materials. The technique is fast, easy to use, requires little training and yields consistent results. The selective action on different phases, and the relationship of secondary electron yield to atomic number makes it easier to interpret the microstructures using the SEM.

\section{References}

1. J. F. Radavich, "Metallography of Alloy 718," Journal of Metals, Vol. 40, No. 7, July 1988, p. 42. 
2. J. F. Radavich, "Longtime Stability of a Wrought Alloy 718 Disk," Superalloy 718 Metallurgy and Applications, ed. by E. A. Loria, pub. by The Minerals, Metals \& Materials Society, 1989.

3. G. E. Korth and C. L. Trybus, "Tensile Properties and Microstructure of Alloy 718 Thermally Aged to 50,000h," Superalloys 718,625 and Various Derivates," ed. by E. A. Loria, pub. by The Minerals, Metals \& Materials Society, 1991. 